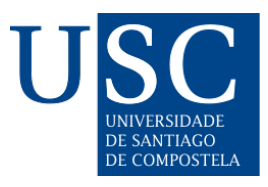

\title{
ETA y la conspiración de la heroína
}

\section{David Mota Zurdo}

Coordinador del grado en Historia y Geografía Universidad Isabel I, España david.mota@ui1.es

A principios de la década de 1980, Euskadi Ta Askatasuna (ETA) y su brazo político, Herri Batasuna (HB), denunciaron en el diario Egin, próximo a la citada coalición política, que las Fuerzas y Cuerpos de Seguridad del Estado (FCSE) habían contribuido al aumento del consumo de estupefacientes en el País Vasco con el objetivo de eliminar a las generaciones jóvenes más reivindicativas. Una tesis conspirativa que, empero, partía del siguiente hecho real: durante los años 80, el consumo de drogas marcó gravemente el territorio vasco y el desvío de los esfuerzos policiales a la lucha antiterrorista hizo que la batalla contra la droga quedara en un segundo plano.

Aprovechando esta circunstancia concreta, se construyó una tesis conspirativa que con diferentes variantes se mantiene aún en activo. De hecho, en 2017, en Ganbara, el programa de Radio Euskadi que conduce Roge Blasco, Justo Arriola -autor de A los pies del caballo. Narcotráfico, heroína y contrainsurgencia en Euskal Herria, Tafalla: Txalaparta, 2016- y Juan Carlos Usó -autor de ¿Nos matan con heroína? Sobre la intoxicación farmacológica como arma de Estado, Bilbao: Libros Crudos, 2015-, debatieron largo y tendido sobre el consumo de droga durante los años 80. En ese espacio radiofónico ambos defendieron dos tesis contrapuestas: para el primero estaba claro que hubo una oferta desmesurada de heroína, fruto de la premeditada voluntad de las FCSE para que se extendiera por las calles del País Vasco; mientras que el segundo opinaba en base a su investigación que, si bien pudo existir una alta oferta, nadie obligó a los jóvenes a consumir la droga. Para Usó no había evidencias consistentes del papel que pudieron jugar los cuerpos policiales en el aumento de los niveles de drogadicción. Sin embargo, para el autor vasco la heroína se había utilizado como arma de Estado para "desactivar la insurgencia social y armada de Euskal Herria"1.

Tiempo antes del citado debate, la investigación de Usó había desmontado con diferente documentación la teoría conspirativa, pero el libro de Arriola, del que se hicieron eco diferentes medios de comunicación para contribuir a su difusión, reavivó la tesis de la maquinación policial y puso en primer plano la teoría de que la lacra de la droga en el País Vasco había sido fruto de una conspiración de las instituciones del Estado contra la juventud política radical. Hasta ahora.

En 2019 Pablo García Varela arrojó luz a esta conspiración en su tesis doctoral El mundo de las drogas en el País Vasco y su relación con el Movimiento de Liberación Nacional Vasco (MLNV), defendida en la UPV-EHU y magníficamente dirigida por dos de los principales especialistas en la historia de ETA de nuestro país (Antonio Rivera y Gaizka Fernández), cuya contribución, no cabe duda, ha sido fundamental para que el citado autor haya conseguido un trabajo redondo que ha culminado, un año después, en una versión divulgativa titulada ETA y la conspiración de la heroína. 
En esta obra ha puesto manifiestamente más claro que la tesis conspirativa inaugurada por la organización terrorista y su rama política fue utilizada por ETA para legitimar sus campañas antiterroristas de eliminación estratégica de elementos policiales, a los que señaló como principales suministradores de droga. Estos argumentos les sirvieron para crear estructuras antisistema a diferentes niveles, sobre todo locales, dominadas fundamentalmente por el nacionalismo vasco radical y erigirse como los protectores de la juventud vasca.

Dando rienda suelta a la teoría, ya apuntada, de que las FCSE habían planteado como supuesta estrategia de desactivación de la juventud "alegre y combativa" del País Vasco llenar las calles de Euskadi con heroína, ETA trató de mostrarse como un instrumento de lucha eficaz, presentándose como juez y verdugo para así eliminar camellos y chivatos de la policía. Pero esta argumentación conspirativa mediante la que se trató de explicar un supuesto plan maligno orquestado por el Estado no es más que una leyenda urbana reciclada con variantes regionales por toda Europa, como afirma García Varela en la obra.

Al margen de esta tesis principal, construida con argumentos sólidos y una profusa utilización de fuentes de diversa índole (bibliográficas, hemerográficas, archivísticas y entrevistas a algunos de los principales protagonistas) se tocan asuntos poco conocidos, insuficientemente demostrados o rumores de la vox populi con voluntad de desmitificarlos y esclarecerlos: al fin y al cabo, esa es la labor de un investigador.

En este sentido, ETA y la conspiración de la heroína se hace eco de la supuesta implicación de la organización terrorista vasca en el narcotráfico: un mecanismo que, según Eli Galdós, viceconsejero de Interior del Gobierno Vasco en 1985, había sido utilizado para la financiación de su actividad armada. García Varela, que ha tenido acceso a informes de la Central Intelligence Agency (CIA) de los años 80, hace referencia a esta cuestión, pero no profundiza demasiado en ella porque considera que no fue la vía de financiación habitual. Por eso, dedica mayor atención al tráfico de armas y a las conexiones internacionales de la banda terrorista vasca.

De este modo, García Varela afirma que, así como ETA pudo traficar con armas, no se ha probado que la organización estuviese involucrada "en tramas delictivas asociadas al narcotráfico". Si bien, para "legalizar" el dinero del impuesto revolucionario y los secuestros, no tuvieron reparos en hacer negocios con organizaciones mafiosas que sí se dedicaron a ello y que trabajaron para narcotraficantes y otras organizaciones. Por eso, que en la década del 2000 Roberto Saviano vinculara a ETA con los negocios de la Camorra y las Fuerzas Armadas Revolucionarias de Colombia (FARC), no significa que realmente los terroristas vascos utilizaran el narcotráfico como vía de financiación habitual.

Aunque en la obra de García Varela se dé en parte carpetazo al vínculo entre ETA y el narcotráfico aduciendo que no hay evidencias suficientes, sí que hay otras cuestiones en las que éste podría haber profundizado a un nivel micro, como es el supuesto uso que, según la CIA, hizo ETA de pequeños traficantes de droga dedicados al "menudeo" y el "trapicheo". No en vano, puesto que utiliza fuentes estadounidenses, cabe indicar que hay varios informes de la agencia de Inteligencia y de la embajada de EEUU en Madrid en los que se señala que algunos miembros de ETA usaban drogas y traficaban ocasionalmente con ellas. Ciertamente, y he aquí uno de los motivos por los que quizá el autor de esta obra no profundice en ello, la CIA dudó desde el primer momento que ETA estuviera involucrada en el narcotráfico, pero sí consideró relevante que esta utilizara "a los traficantes de drogas como agentes y correos de bajo nivel" ${ }^{2}$. 
Obviamente, la relación entre determinados miembros de ETA y toxicómanos ocurrió a nivel local, porque se ha probado que hubo terroristas que fueron amigos de camellos, y que hubo adictos que fueron afines al nacionalismo vasco radical, pero se desconoce si su uso fue continuado o respondió a algún tipo de estrategia instrumental. La relación de ETA y el nacionalismo vasco radical con las drogas fue muy compleja y se compuso de diferentes tramas. García Varela ha arrojado bastante luz al respecto al demostrar que la organización terrorista tuvo la oportunidad de involucrarse de manera más decidida en el narcotráfico, pero que no lo hizo por problemas estructurales internos y el impacto de la droga sobre sus miembros.

Como ya pusiera de manifiesto la CIA en 1983, varios miembros de ETA usaron drogas y fueron adictos a la heroína. Así lo demuestra el autor en esta obra destacando que un significativo número de etarras sufrieron esta adicción. Y es que el rechazo de la cúpula de ETA a narcóticos como la heroína no impidió que en su seno hubiera miembros toxicómanos, como destaca García Varela: el miembro de ETA José Luis Oliva fue asesinado por sus colegas del comando Orbaiceta por haber desviado fondos de un atraco para costearse su adicción y Pedro Mariñalera fue un heroinómano, miembro de la organización terrorista, que acabó infectándose de VIH.

Al margen de las contradicciones de ETA y su relación con el mundo de la droga, la realidad es que esta organización asesinó a 43 personas bajo el pretexto de ser narcotraficantes y chivato. de la policía: adictos, personas del lumpenproletariado y empresarios con negocios de ocio fueron los principales blancos de ETA, contra los que apretó el gatillo por el simple rumor o como mecanismo de justificación de sus acciones contra aquellos que se negaron a ceder ante el terrorismo y la extorsión.

Así sucedió, por ejemplo, con Arturo Quintanilla, propietario del bar José Mari de Hernani, que fue asesinado por ETA como castigo ejemplarizante para aquellos que no accedieran a las exigencias de la banda. La organización terrorista negó rotundamente que el asesinato fuera el resultado de la negativa de la víctima a pagar el impuesto revolucionario y la acusó "de ser un informador de la policía y un traficante de heroína” ${ }^{3}$. El caso de Miguel Paredes y Elena Moreno fue parecido. Como recoge García Varela, estos fueron acusados de ser adictos y traficantes de estupefacientes y, por eso, el joven matrimonio fue asesinado por ETA en San Sebastián. Posteriormente, fue estigmatizado al definirles como delincuentes comunes por parte de ciertos sectores de la sociedad civil. Sin embargo, tiempo después, se demostró que no eran toxicómanos, sino simplemente una pareja como cualquier otra.

Con sus errores y aciertos, ETA y la conspiración de la heroína es una aportación historiográfica muy significativa, que no está reñida con la alta divulgación científica. Su relato es desmitificador al clarificar la vinculación entre ETA y el mundo de la droga y desmontar la tesis de la conspiración por la que se habría introducido la heroína en el País Vasco. Aporta gran número de datos inéditos y pone el foco tanto en las víctimas de ETA acusadas de tráfico de droga como en los terroristas adictos a la heroína. Lo hace, además, en un texto asequible, con una extensión bastante reducida (252 p.), que contribuye a que la lectura sea amena, profunda y reflexiva. Sin embargo, es obligado señalar que, aunque los avances en la investigación logrados por el citado autor son notables, los claroscuros continúan y se abren otros caminos de investigación que convendría sondear en un futuro, como es el supuesto empleo de camellos en las actividades de seguimiento e información de la banda para cometer actos terroristas. 


\section{Información Adicional:}

Título: ETA y la conspiración de la heroína

Autor: Pablo García Varela

Editorial: Catarata

Año de edición: 2020

Páginas: 252

ISBN: 978-8413520544

NOTAS

1 Justo Arriola: "El GAL nos enseñó que algunos saben aunar el interés contrainsurgente con el afán de lucro", Txalaparta web, 10-V-2017. Recuperado de https://www.txalaparta.eus/es/noticias/el-gal-nos-enseno-que-algun os-saben-aunar-el-interes-contrainsurgente-con-el-afan-de-lucro

2 Terrorism review, 1-IX-1983, GI-TR 83-018, CIA-RDP84-00893R000100240001-4.

3 Terrorism review, 29-IX-1983, GI TR 83-020, CIA-RDP84-00893R000100260001-2. 